\title{
Ecotourism and the politics of representation in Fiji
}

\author{
Holger Korth
}

\section{Introduction}

Development initiatives in the South Pacific have intruded in often harmful ways on indigenous people's lives. Indeed, many projects have become examples of 'maldevelopment' (Emberson-Bain 1994c). This has led to the search for alternative development options. In recent years this search has fostered the emergence of the discourse of sustainable development. In essence, sustainable development promises holistic solutions to maldevelopment, solutions that are guided by sociocultural and environmental considerations. In the South Pacific, this discourse has in particular been articulated as the solution to the diverse range of economic, social and environmental problems associated with the tourism sector.

Since the mid 1980s development assistance programs in Fiji have sponsored sustainability-based ventures in the tourism industry. These ventures are now commonly called 'ecotourism'. Major donors have included multilateral aid agencies such as the United Nations Development Programme (UNDP) and the South Pacific Regional Environmental Programme, as well as the official development assistance of regional industrialised countries. For example, the New Zealand Official Development Assistance program (NZODA) has sponsored ecotourism projects in Fiji's rural tourism periphery. The rationale for such support is clear. According to NZODA, ecotourism offers a sustainable alternative that not only helps combat environmental degradation and achieve economic growth but also 
provides an alternative to capital-intensive, large-scale mass tourism development by creating business opportunities for rural communities (New Zealand Ministry of Foreign Affairs and Trade 1995). With such overseas economic assistance, it is perhaps not surprising that tourism planners in the Fiji government have shown a growing enthusiasm for ecotourism. It is also not surprising that indigenous Fijian landowners have welcomed ecotourism, predicated as it is supposed to be on the principle of sustainability, as an attractive development option (Cabaniuk 1989; Wakelin 1991).

However, despite widespread and growing support for ecotourism in Fiji, the belief that ecotourism is a clearly delineated development alternative is erroneous. While ecotourism ideally denotes nature and culture-based tourism that involves active appreciation, education or interpretation (Backman 1994), in practice it is not the panacea for maldevelopment that many purport it to be. Moreover, it has in reality often been applied to virtually any kind of tourism which has even the vaguest connection with nature (Harrison and Brandt 1997) or with culture (Helu-Thaman 1992). This chapter ${ }^{1}$ will illustrate that both of these propositions apply to Fiji.

The chapter begins by offering a brief outline of the impact of 'traditional' mass tourism in Fiji, in order to contextualise the evolution of ecotourism. It will be argued that the negative aspects associated with mass tourism led to a search for innovative solutions, which then acted as catalysts for the emergence of an alternative tourism planning discourse in Fiji. This is witnessed in planning documents that sought to incorporate Fiji's natural and cultural heritage as tourism assets. This process led to the establishment of the so-called 'secondary tourism' sector, which laid the foundation for the emergence of ecotourism.

The principal govemment institutions involved in the establishment and development of ecotourism in Fiji have been the Native Lands Trust Board (NLTB) and the Ministry of Tourism (MOT). As will be seen in the chapter, the NLTB has become increasingly concerned with policy development and implementation, while the MOT has utilised ecotourism as a marketing tool in order to remodel the image associated with the secondary tourism sector. However, ecotourism representations have not only remodelled the images associated with the culture and natural heritage of Fiji, but have also remodelled more traditional tourist attractions. This demonstrates the problematic status of the ecotourism label. At the same time, despite these 
remodelling efforts the economic returns to ecotourism have been low. As will be shown, rural initiatives have not become commercially selfsufficient, nor have they met financial expectations, even though the ecotourism label has been part of mainstream tourism promotions ${ }^{2}$.

Finally, in order to complement the analysis of ecotourism's conception, gradual implementation and economic performance, the chapter will evaluate its cultural impact on post-coup Fiji. It will be argued that compared to ecotourism's limited economic role, its cultural significance has been disproportionate. While ostensibly seeking to provide resources to rural communities as a means of promoting localised nature conservation, ecotourism has in fact reflected communalist divisions. Representations of ecotourism have been politically motivated and ethnically biased towards the indigenous Fijian population. Ecotourism discourse has thus become tied into a wider discourse, that of communalism.

\section{Mass tourism in Fiji}

Since the 1950s, intercontinental air travel has enabled fast and relatively affordable access to Fiji, leading to rapid growth in the tourism industry. Air travel to Fiji increased by about 20 per cent annually between 1965 and 1973; in 1973 186,000 visitors arrived by air. Apart from temporary slumps as a result of the oil crisis in 1974 and cyclones in 1983 and 1985, visitor arrivals continued to increase by nearly 4 per cent a year up to 1986. After the military coup in 1987 arrivals temporarily fell to 189,900 , a drop of 26.3 per cent. However, by 1995 numbers had almost doubled to 359,400 . By the mid 1990s tourism was, at 18.3 per cent of GDP, more important to the economy than sugar, which generated 11.4 per cent of GDP (Fiji Visitors Bureau 1995; Fiji Bureau of Statistics 1997).

Tourist expansion concentrated notably on western Viti Levu, the Coral Coast, and the Yasawas and Mamanucas; the spatial integration of remoter islands into the tourism industry only partially took place. Thus, the Nadi area attracted 31 per cent of hotel visitor bed nights in 1995, while the Coral Coast and the Mamanucas and Yasawas attracted 31 per cent and 20 per cent respectively. In contrast to these flows to Fiji's tourism 'centre', the frequency of visitation by tourists to the more 'peripheral' outer islands was, at 4 per cent of visitor bed nights, much lower (Ministry of Tourism and Civil Aviation 1995b). 
Growing visitor numbers encouraged the colonial administration to provide legislative support for tourism development, in the form of the Hotel Aids Bill of 1958 and the Hotel Aid Ordinance of 1958, which was rewritten in 1964. The legislation respectively liberalised duty free trading and offered substantial economic incentives to encourage the construction of new hotels. Foreign consultants meanwhile advised successive Fiji administrations to focus on large-scale tourism development as an alternative development option designed to reduce the economy's dependence on the production of sugar.

Ambitious tourism development initiatives sought to capture economies of scale; in practice this meant that proposed projects were frequently too capital-intensive to be locally funded. State policy was thus strongly biased in favor of attracting international capital to supplement any investment made by the expatriate business community that had come to dominate the local economy. As a result, Fiji's tourism industry was an early site of contestation between local investors who received token concessions from the state, and foreign interests, who sought to consolidate their control of the tourism sector (Britton 1983; Britton and Clarke 1987; Plange 1996). Over time, many local entrepreneurs were pushed to the margins of the industry.

By the 1970s, the predominance of foreign capital in the tourism sector led some to argue that it was a new form of colonialism that reinforced relations of dependency on metropolitan core capital (Britton 1980). In large part, this was because of the fact that as the tourism industry became predominantly foreign owned, increases in tourism receipts were offset by revenue leakages. Retention of earnings from prepaid tour packages by expatriate agencies, as well as the need to import fuel, food, construction materials and expertise, contributed to the substantial leakage of tourism revenues out of the economy. In 1975 the leakage of earnings amounted to 70 per cent of total revenues (Britton 1980:148). Indeed, even in 1996 revenue leakages remained around 44 per cent of tourism earnings (Tabua 1996). There can be little doubt that the leakage of tourism revenues slowed the pace of socioeconomic development in Fiji.

Large-scale tourism has increasingly drawn Fiji into a globalised modernity, and rapidly growing numbers of visitor arrivals have continued to accelerate this process. However, mass tourism development in the postcolonial period has to some extent been dependent on Fiji's pre-existing colonial infrastructure (Britton 1980); 
it has thus brought less economic development of benefit to wider Fiji society than might be supposed. Moreover, mass tourism's human development impact on both the indigenous and the Indo-Fijian communities has remained limited (UNDP 1994). These shortcomings have not gone unnoticed. A growing concern in Fiji has been how to redress the flaws of conventional tourism development. These concerns have found expression in planning discourse and policy development, at both the regional and local level.

\section{Ecotourism, planning discourse and policy development}

Given the flaws of mass tourism, ecotourism initiatives have developed in Fiji in the period since 1986. These initiatives emerged through a succession of policy planning documents that increasingly noted the possibilities of rural ecotourism as a means of combatting uneven development, enhancing autonomy in the tourism industry, and promoting community involvement. In this section four such plans are examined. These plans demonstrate how ecotourism came to be incorporated within planning discourse in Fiji, in large part because of a rising awareness within the NLTB of the possible importance of Fiji's unique natural environment and indigenous culture in sustaining localised tourism initiatives in the rural economy, an awareness that found expression in NLTB policy.

\section{The Belt Collins Report}

The 1973 Belt Collins Report was jointly commissioned by UNDP, the International Bank for Reconstruction and Development, and the Government of Fiji. The purpose of the Report was to establish Fiji's first comprehensive tourism development program and, at face value, the report did indeed maintain a conventional expansionist perspective towards the development of Fiji's traditional mass tourism market. Promotions were to focus on 'sun, sand, sea and smiles', while economic incentives were to be geared towards attracting inward investment from foreign capital. According to the Report

the obvious solution [to tourism development] is to attract capital from overseas, but it is equally obvious that overseas capital will remain in its own region unless there is sufficient incentive to motivate its own movement (Belt Collins and Associates 1973:184). 
However, although understated, the Report did contain a skeleton of ideas and criteria, including concern for the community, the environment, and education, which, as we will see, became central to landowner-operated ecotourism initiatives during the 1990s. Thus, the Report noted that a balance needed to be developed so that the potentially substantial economic benefits of tourism could go hand in hand with maintaining Fiji's cultural integrity. It was in this context that the section on 'visitor attraction' urged that attention be paid to the cultural impact of tourism, in order to mitigate any possible social conflict. Moreover, a growing cultural and environmental awareness was expressed in recommendations for the preservation of significant archaeological and historic features. At the same time, and of particular significance for the future development of ecotourism, the Report urged that national parks be designated as 'tourism assets'. Finally, and more generally, the Report argued that tourism development should encourage

the spreading of the economic benefits of tourism throughout the society, providing the opportunity for Fiji citizens to participate in and control the industry...[T]ourism...[is] a means of residents learning from visitors as well as visitors learning from residents...[and] a means of cultural and environmental conservation...[V]isitor facilities [should be] based on the local environment and culture so that residents can relate to the facilities and have a sense of pride in their heritage...[E]ducation and training of residents to work in tourism...[should provide] for adequate housing and community facilities for persons employed in tourism (Belt Collins and Associates 1973:17).

There can be little doubt that these ideas contributed to the evolution of the concept of ecotourism in Fiji. Nonetheless, while over the course of the late 1970s and early 1980s the tourism sector started to diversify, much remained to be done. For example, in 1986 a visitor's survey carried out in Nadi revealed that visitors felt Fiji holidays offered little in the way of diversion and few places to visit (cited in Sawailau 1996). Clearly, shifting consumer needs and perceptions indicated a need for change. However, the conceptual roots of later ecotourism initiatives still needed to be fully elaborated. 


\section{Fiji's Ninth Development Plan}

Until 1986, government economic policy was based on five-year development plans. The last of these was the Ninth National Development Plan (DP9), designed to cover the period between 1986 and 1990. The strategy of this last five-year plan was neoliberal, emphasising the promotion of export-led growth, the phasing out of tariffs and trade restrictions, the corporatisation of the state-owned enterprises, labour market reforms, and the deregulation of the financial and service sectors (Government of Fiji 1986; Chandra 1988).

The objectives for the tourism sector in DP9 were decidedly economistic: the maximisation of the net value of tourism earnings was emphasised. Nonetheless, in DP9 one of the nine separate tourism sector programs that was elaborated was dedicated explicitly to the promotion and development of so-called 'secondary tourism' activities by local entrepreneurs, through the provision of basic infrastructure, physical resources and credit facilities. This was to encourage 'local people to establish rest homes and long distance cross-country walking trails... [and] the provision of facilities for horse riding, river rafting, diving and other secondary activities' (Government of Fiji 1986:87). The plan explicitly noted that 'to encourage...local participation, the entry of expatriate operators in these [secondary tourism] areas will be discouraged'. The plan further set out the government's intention to maintain the 'judicious' utilisation of resources, which, according to Weaver (1994), allowed environmental management to form an integral part of development planning.

Thus, DP9 contained two elements of future ecotourism initiatives: one, its promotion of greater 'local', by which is meant indigenous Fijian, participation in all sectors of the tourism industry; and two, its advocacy concerning the need to protect and conserve the natural environment. Thus, environmental conservation and the provision of business opportunities for indigenous Fijians in the tourism industry, concerns which had been present, if understated, in the Belt Collins Report, became legitimate parts of Fiji's planning discourse. In the years following the coups, these aspects increasingly came to the fore. 


\section{The Cleverdon and Brook Report}

In 1986 and 1987 a comprehensive review of alternative tourism in Fiji was comissioned by UNDP, under the auspices of the World Tourism Organisation. This review culminated in the publication of the Cleverdon and Brook Report (1988). The Report provided a thorough assessment of what was then conceptualised as the 'fledgling field' of secondary tourism. Secondary tourism was used

to refer to all activities in which tourists and recreating Fijians may engage, and for which facilities may be provided on a commercial basis, which are not 'mainstream' resort accommodation or transport operations, either in respect of their style, or location/area of operations.

It argued that

Secondary tourism activities typically take place in rural regions where there is little, or no, previous tourism development (ie off-thebeaten-track) and the tourism operations catering for such activities are operated and controlled by Fijians, in line with recommendations outlined in DP9 that such operations are to be reserved for Fijian interests (Cleverdon and Brook 1988:4).

The Report went on to more precisely define secondary tourism as: water-based activities, including scuba diving, surfing, and boating; land-based activities, including trekking, secondary accommodation and village tourism and entertainment; and 'general possibilities', including plantation and farm visits, anthropology, archaeology, forests, landscapes, mountain climbing, and ornithology (Cleverdon and Brook 1988:28-80).

The contents of the Report had implications for the emerging discourse of ecotourism. For a start, the Report displays the bias of expatriate discourse. In particular, references to local cultural idiosyncrasies are minimal. Thus, the discussion of the role of local communities and their need to mediate the social and cultural impacts of secondary tourism is very brief, pointing towards a lack of acquaintance with local knowledge and sensitivities. At the same time, the Report's definition of secondary tourism identified a vast range of activities. As will be seen, the broad definition of secondary tourism has had a direct impact on ecotourism, in that it has become an imprecise classification which eludes clear definition. 


\section{The Coopers and Lybrand Tourism Masterplan}

In 1989 the Coopers and Lybrand Tourism Masterplan was published. The Masterplan called for higher levels of public sector support in the tourism sector, recommended implementation of social monitoring and public awareness programs, and explicitly advocated the provision of safeguards for the natural environment through the creation of nature reserves and recreation areas, as had been called for in the Belt Collins report (Coopers and Lybrand Associates 1989). At the same time, the Masterplan recognised the potential of secondary tourism. The Masterplan's chapter on secondary tourism proposed the development of culture and environment-based activities. It called for the identification of avenues to promote greater local community participation, including the recommendation that effective training programs be implemented in order to increase local participation in secondary tourism. Finally, like DP9 the Masterplan endorsed discouraging foreign involvement in secondary tourism, in part because of the supposition that it had low capital and technology requirements.

The Masterplan's elaboration of the concept of secondary tourism demonstrated the extent to which environmental conservation, the provision of entreprenurial alternatives for indigenous Fijians in the tourism industry, and the opportunities provided by indigenous Fijian culture were becoming part of 'mainstream' discourse in the tourist industry. Clearly, policy advice for Fiji's tourism industry was moving closer towards what would later be regarded as ecotourism. Aspects of each of the four documents just discussed therefore contributed to the formation of the concept of an environmentally-based, sustainable tourism.

\section{The NLTB and tourism policy}

Alongside the documents just discussed a fifth intervention should be seen as having contributed to the formation of the concept of ecotourism and its entry into Fiji's planning discourse: the NLTB's tourism policy. Whereas each of the four documents elaborate possibilities, the NLTB has formulated and implemented tourism policies which have facilitated the beginning of experimental tourism initiatives and which moreover point to possible ways in which an environmentally-based, sustainable ecotourism may develop in the future. 
Since 1946 the NLTB has had the responsibility of administering the 83 per cent of Fiji's total land area which is classified as 'native land'. This has been done on behalf of the indigenous Fijian landowning groups who were assigned title (Prasad and Kumar, this volume). As the most important institution designed to administer land in Fiji, the NLTB has emerged as a powerful leader in sustainable resource management. The sustainable land management policies of the NLTB have evolved over time through a series of documents: the NLTB (1985) Policy on the Logging of Indigenous Forests; the Policy for Tourism Development on Native Land 1990-95 (NLTB 1990); the Environmental Charter (NLTB 1992); and the Tourism Policy for Native Land 1997-2000 (NLTB 1996; see also Cabaniuk 1996). These documents, and the policies which they have produced, have developed a greater clarity concerning the need to ensure that Fiji's natural environment is safeguarded, that indigenous Fijian lands are developed and used in a sustainable fashion, and that the cultural heritage of indigenous Fijians is preserved.

It is the Board's Landuse Planning Section which is the local leader in current ecotourism development efforts. In so doing, the NLTB is following the medium-term policy direction envisaged in the government's 1993 economic strategy, which included the promotion of ecotourism in order to enhance an awareness of Fiji's ecology and cultural heritage while at the same time ensuring enhanced indigenous Fijian participation, particularly in rural areas (Government of Fiji 1993). As a consequence, in partnership with indigenous Fijian landowners the Landuse Planning Section seeks to link ecotourism development with the conservation of nature, the protection of Fiji's heritage, and community development. In order to do this, the Section chairs and provides the secretariat for the interdepartmental Native Lands Conservation and Preservation Projects Steering Committee (NLCPPSC). The NLCPPSC was founded in 1991 to provide input into NZODA projects and is a multi-sector advisory panel including representatives from the Ministry of Tourism and Civil Aviation, the Ministry of the Environment, the Department of Forestry, the Fijian Affairs Board, the Fiji Development Bank, the Fiji Museum, the National Trust for Fiji, and Fiji Pine Ltd. The group meets irregularly to discuss environmental conservation projects. The Section has also prepared an enviromental policy statement; it has worked directly with landowners to promote ecotourism around 
forest conservation; and it has been working with the Fiji Museum on an integrated educatational ecotourism package tour (Matararaba and Cabaniuk 1996).

The Landuse Planning Section is currently seeking to facilitate enhanced coordination and management of tourism development across the regions, by working towards the establishment of a nation wide system of forest conservation areas, reflective of recommendations in the government's National Environment Strategy (Watling and Chape 1993). These forest conservation areas will be communitybased, and should form a keystone for both rural ecotourism initiatives and the protection of Fiji's natural environment.

It is thus reasonably clear that over the last two decades planning discourse and policy interventions in Fiji have started to incorporate concerns regarding the impact of tourism on the natural environment and on indigenous culture. Ecotourism has as a result become conceptually embedded within the dominant planning discourse. This has been particularly the case since the late 1980s, when the need to mitigate the negative economic, sociocultural and environmental impact of conventional mass tourism became increasingly apparent. In recent years interventions by the NLTB in the field of secondary tourism perhaps demonstrate most clearly the growing conceptual power of ecotourism.

Thus far this chapter has emphasised the development of the concept of ecotourism in Fiji through an interpretation of planning and policy texts. However, the development of ecotourism in Fiji warrants a wider reading. In particular, it is necessary to take account of the evolution of the concept as a reflection of political agency within the MOT. By changing the angle of observation in this direction, the polysemy of ecotourism representations and terminology will become apparent.

\section{The MOT, ecotourism and changing significations}

The use of ecotourism as a label in Fiji can be traced back to the early 1990s, when concern grew within government and industry over secondary tourism's negative image as 'second best' tourism. Institutions involved in travel promotion and tourism marketing were weary of this negative connotation, prompting MOT officials to seek to replace the label with a more positive term (Schuller 1996: personal 
communication; Sawailau 1996: personal communication). As a result, during the early 1990s ecotourism began to replace secondary tourism as a marker for sustainable tourism initiatives. Of course, ecotourism is not a hermetically sealed concept. It is however a convenient rhetorical device.

The reinvention of secondary tourism as ecotourism coincided with the establishment of the MOT's small Ecotourism Unit in 1993, which was given a brief to further the understanding of ecotourism and advance the perceived benefits of it through the establishment of education and training programs. The Unit was to coordinate the development of Fiji's cultural, natural and historical resources as tourist attractions (Fiji Ministry of Tourism and Civil Aviation 1995a). Furthermore, it was to render advisory assistance to the private sector, support ecotourism marketing initiatives, and develop policy directives. Finally, it was to strengthen relationships between various government departments with a stake in either tourism or the environment (Francis 1994).

In so doing, the Ecotourism Unit had to deal with intragovernmental contestation concerning the development, classification and implementation of ecotourism: without doubt, at times, only nominal cooperation between departments occured. For example, despite regular meetings that were held under the umbrella of the NLCPPSC, members claim that feedback from individual departments for its initiatives, recommendations and development strategies remained extremely low. In part, this was due to certain sections in the civil service which were too conservative in their attitude to change. Innovation has often been stifled by a public service ethos in Fiji that sanctions adherence to hegemonic power structures. Influenced by the prominence of the chiefly system, an established culture of tradition, especially among non-unionised sections of the public service, has been perpetuated (Leckie 1997b). At the same time, the Ecotourism Unit has had to deal with diverse and at times conflicting interests amongst those with a stake in ecotourism. In addition to the members of the NLCPPSC, players with a stake in ecotourism include the Department of Town and Country Planning, the Lands Department, the Fiji Trade and Investment Board, the Fiji Ecotourism Association, the Fiji Hotel Association, the Tourism Council of the South Pacific, the Foundation for the Peoples of the South Pacific, NZODA, and UNDP. 
In a bureaucratic environment that is averse to change, the Ecotourism Unit had the difficult brief of implementing an innovative concept. One of its first objectives was to raise ecotourism's public profile. Promotional articles were compiled and stronger liaising between various government departments with a stake in tourism and the environment advocated. More directly, in 1993 a series of Fiji National Heritage Posters was launched as the result of successful collaborative efforts between the Ecotourism Unit, the Ministry of State for the Environment, and to a lesser degree various other departments, including the NLTB and the Fiji Museum. Conceived as a linchpin in the development of ecotourism (Francis 1994), the posters vividly expressed a move away from Fiji's 'sun, sand, sea and smiles' image by fostering an appreciation of both the environment and of culture while at the same time conveying linkages between conservation and heritage.

The heritage poster series depicts particular aspects of selected landowner-operated ecotourism ventures such as the waterfalls at Bouma and archaeological features of the Tavuni Hill Fort. It also included images of native fauna such as the crested iguana, along with more surreptitious features such as World War II sites and depictions of Fiji's Parliament. Thus, under the heritage umbrella, themes were used to rightly or wrongly identify, define, and represent ecotourism. The selection of themes and images is consistent, with a bias towards those aspects of the environment and culture that lend themselves to commodification as tourism assets, thus selectively prioritising the preservation of reified places, environmental features and cultural artefacts.

\section{Ecotourism classifications and definitions}

As a new marker that replaced the label of secondary tourism, ecotourism offers an alternative mediation of reality. Its image allows for the invention of a hyperreality in which its products appear more authentic, more real, and more traditional than conventional tourism products. Over the last five years, the MOT has harnessed this image to denote innovative tourism ventures as well as reinvent selected traditional mass tourism attractions. This can be witnessed in the eclectic ecotourism classification system produced by the MOT. Listed 
ecotourism ventures include privately run hotel accommodation, tribally operated nature trails and tourist lodges, as well as mainstream cultural attractions such as the Fiji Museum and the Pacific Harbour Cultural Centre. Indeed, even general public transport operators such as Air Fiji are included (Fiji Ministry of Tourism and Civil Aviation 1996). It thus becomes apparent that the branding of ventures with the label 'ecotourism' has occurred on an ad hoc basis, comprising a diverse selection of tourism projects and operators. The heterogenous character of registered ecotourism ventures reflects not only on the success of the label and the image as a marketing tool, but is also the result of differing definitions of what constitutes ecotourism amongst diverse groups-definitions that have at the same time been subject to change.

There are two explanations as to why ecotourism has attracted such a diverse range of groups. On the one hand, ventures may have been deliberately incorporated in order to become associated with an attractive image that enhances commercial possibilities. On the other hand, the ad hoc fashion in which the terminology has been applied suggests that definitions have lacked clear direction and have thus allowed for the identification of a wide range of very different ventures.

Indeed, the definition of ecotourism used by the MOT has been variable. At one time, two different definitions were published by MOT employees within a single year (Sawailau 1994; Francis 1994). However, while precise definitions have changed, over a two-year period in the mid 1990s the general meaning of ecotourism contained three common themes: ecotourism should supplement the subsistence economy of indigenous Fijian landowners by providing opportunities for employment and the enhancement of communal resources; it should conserve the environment by minimising the negative impact of tourism; and it should sustain traditional cultural identities by promoting two-way interactive experiences which educate visitors in the cultural and environmental activities of indigenous Fijians. A concern with nature is thus arrayed with culturally essentialist notions of tradition and identity and articulated within a terrain dominated by economic logic.

The latest policy draft of the MOT on ecotourism is more comprehensive than previous efforts, indicating that ecotourism should be small scale, labour intensive, locally owned and operated, 
and involve fewer leakages than mass tourism (Harrison 1997). Nonetheless, the draft continues to perpetuate bounded and functionalist concepts that value yet at the same time seal the environment and culture in a seemingly timeless shell. For example, the draft defines ecotourism as

a form of nature-based tourism which involves responsible travel to relatively undeveloped areas to foster an appreciation of nature and local cultures, while conserving the physical and social environment, respecting the aspirations and traditions of those who are visited, and improving the welfare of local communities (Harrison 1997:5).

The definition continues to perpetuate, if ever so slightly, a particularistic vision of indigenous Fijian identity. Of course, any attempt to classify or essentialise ecotourism, as is attempted in the draft, is inevitably reductionist. Ecotourism's definitional transience resists closure, and it is quite possibly an unworkable task to create a comprehensive classification system based on a term that is subject to constant change.

\section{The economic significance of ecotourism}

Despite the continued emphasis within Fiji ecotourism on the importance of indigenous Fijian culture, very few of the projects listed as ecotourism by the MOT are run on communal principles, which form the basis of many indigenous Fijian social institutions; private sector ventures predominate. These private sector enterprises are however caught in a sharp contradiction. For ecotourism to maintain its distinctiveness from mass tourism, it will have to remain a fringe activity. However, with only a limited number of tourists participating in ecotourist activities, activities which are predominantly small in scale, the income generated has remained marginal within the tourist industry as a whole. For example, the income generated by two of Fiji's foremost landowner-operated ecotourism projects-in Bouma and Abaca-barely reached $\mathrm{F} \$ 12,000$ annually by $1996 .{ }^{3}$ Thus, that which is unique about ecotourism may also render it economically unviable. Indeed, in common with many landowner-operated ecotourism projects, substantial funding for the two projects mentioned above had to come from official development assistance. For Bouma and Abaca, establishment costs were almost entirely 
funded by official development assistance from NZODA. Thus, by 30 June 1996 total NZODA expenditure for ecotourism in Fiji stood at NZ $\$ 797,953$, according to officials at the New Zealand Embassy in Suva.

The economic performance of ecotourism in Fiji is questionable, especially to the consultants and policy makers who frequently assess ecotourist initiatives. At the same time, in a society that implicitly sanctions nepotism the distribution of the revenues from ecotourism will continue to lack transparency. This is especially true for landowner-operated ecotourism projects. Thus, in the Bouma project, between 1991 and January 1996 only F\$5,123 had apparently been accumulated 4 . The wider Bouma community enjoyed few tangible returns, and real income distribution apparently centered on the kin group associated with project management.

This indicates the continuing marginalisation of the subaltern majority of rural people involved in ecotourism in Fiji. Fringe benefits to communities are negligible, while low revenue structures keep wage levels at a minimum in the ecotourist service sector. For example, the main benefit from ecotourism for Abaca village was a foreign-funded truck. Little money has been made available to maintain it; in 1996 the driver, working standby, received as little as $\mathrm{F} \$ 50$ for up to 80 hours work.

In part, the poor economic performance of ecotourism is not surprising. Donor pressures continue to influence its pace of development. A good example of this was the controversial appointment of a consultant from the parastatal Fiji Pine Limited (Harrison and Brandt 1997) for rural ecotourism projects in Bouma and Koroyanitu. Since Fiji Pine is a quasi-autonomous agency, it fell outside established channels of communication between government departments. Information flows were subsequently limited and at times failed. Moreover, since the appointment was driven by NZODA both government and the private sector withdrew their support, albeit informally, from the projects, thus laying the groundwork for disappointing economic returns. As is demonstrated in the example, poor communication strategies often mean that donor-driven initiatives in ecotourism negatively affect relations between government departments, the private sector and other bilateral, multilateral and non-governmental donors. They also can fuel the civil service conservatism previously noted. 


\section{The cultural significance of ecotourism}

Indigenous culture has been a major feature in the spread of ecotourism. The perceived exoticism of the culture and people who are indigenous provides the context for a cultural tourism experience. According to Din (1997), the association with 'indigenous' ensures product differentiation in the face of homogenising forces associated with the internationalisation of destinations and economies. However, in order to turn culture into a commodity that tourists can consume, its complex processes and features have to be abstracted and refined so as to become embedded as a consumer product. Li and Butler (1997) argue that commodification may protect a cultural resource, as its maintenance is vital to secure the flow of financial returns that are generated in exchange for cultural experience. Whether this has been or will be the case in Fiji is an open question: the cultural significance of ecotourism is only starting to become clear.

Ecotourism in Fiji has a strong yet relatively little studied ethnic component. In the recent past, the culture of Fiji has been perceived by visitors only as a bonus and not a primary reason for a visit. Thus, in a 1992 international visitor survey 86 per cent of visitors holidaying in Fiji sought 'rest and relaxation'; only 1.88 per cent sought 'Fiji culture' (Fiji Ministry of Tourism and Civil Aviation 1992:B15). For these resort-based visitors, the 'culture' that has been integrated into massbased tourist experiences has been represented as staged events which occur within the overarching infrastructure of the resort. These versions of staged indigenous elements for the tourist gaze (Urry 1990) cannot replace authentic and inimitable indigenous products and elements. The staged event as a literal frontstage spectacle (Goffman 1963) does not meet the need to become acquainted at a more intimate level, where the authentic is spontaneous, unpredictable and unprovoked, and thus allows for the possibility of liminality (Turner 1978). Staged events do not appeal to a desire for escape, but ecotourism does, in promising transcendence.

Similar to the experience of other countries, yet with its own idiosyncratic features, the indigenous tourism components of ecotourism in Fiji are geared towards the desire of many tourists to learn about, witness and experience indigenous cultures ( $\mathrm{Li}$ and Butler 1997). Ideally they foster mutually beneficial exchanges between hosts and guests. However, for the visitor, the focus of acquaintance rests on 
the inwardly gazing private definition of a rediscovered postcolonialand increasingly post-coup-indigenous Fijian self. At the same time though the apparent reciprocal intimacy of the ecotourism experience-for example, overnight stays in villages or participation in kava sessions-is mediated by indigenous hosts. Trajecting their post-independence experience, hosts appear reflexive, and mindful of their different identities during the encounter. Thus, breaches of cultural protocol are met with enormous tolerance. During kava sessions it is common to witness ecotourists getting up to spit the kava out. The insult to the host is usually disguised by their laughter. After all, the host needs to mediate advertised promotional representations that construct them as culturally exotic with non-advertised representations that reveal their economic disadvantage in relation to the affluent who partake of these experiences.

In the wake of the coups, there has been a self-conscious celebration of indigenousness and a growing nostalgia amongst many indigenous Fijians for an illusive past. Post-coup sentiment has become sharply associated with the politics of difference and an exacerbation of communalism (Durutalo 1986). Conflict has emerged between the advancement of a cosmopolitan liberalism, which can be tied to an environmentalist ethos, and the conservation of a rigid and essentialist traditional ethos, which is constructed around an indigenous identity. Ecotourism is positioned at the intersection of this conflict, as it seeks to encompass both the environmental and the cultural.

The experience of culture in post-coup Fiji has been characterised by the widespread fragmentation of traditional sociocultural norms. It has been expressed distinctly along both a geographical rural-urban divide, as well as along ethnic divides, between Indo-Fijian and indigenous Fijian communities. By focusing on indigenous Fijian culture, ecotourism has become an involuntary ally in power struggles that centre around ethnicity. The monopolised domination of a projected ecotourism image focuses singularly on the indigenous ethnie and thus enhances the experience of alienation amongst the nonindigenous population. The tourist gaze marginalises Indo-Fijian experiences and accentuates ethnic divisions.

Thus, the voyeuristic perspective of the tourist in cultural ecotourism unconsciously witnesses and participates in the private struggle to redefine post-independence and post-coup social space that has been prominently associated with communalist identity 
politics. The coercive stifling of the formerly pluralist political landscape has ensured that post-coup identification focused on a unilateral valorisation of ethnic difference. The ecotourism process reflects and contributes to this process. This is a disappointing outcome. Fiji's incorporation into the global economy provides ample opportunities for ethnic barriers to be reduced. In that tourism has not been used to promote an image of emerging cosmopolitan heterogeneity, a chance to reconstitute a national image that would reduce ethnic tension-even if within the context of a re-awakening political pluralism-has so far been missed.

\section{Confronting futures}

Ecotourism neither alleviates the ethnic tensions created as a result of indigenous Fijian identity politics nor does it fulfil the modernist promise of providing socioeconomic returns that can ensure sustained environmental conservation. Thus, as a sustainable development initiative ecotourism has so far failed to counterbalance growing ethnic and financial inequalities in Fiji. Yet the development of a successful ecotourism sector in Fiji faces an even greater challenge. At the core of the development paradox lies a premise of sustainability. That premise promises the recognition and maintenance of tradition and heritage, while simultaneously striving for community development through the establishment of a conservation ethic, democratic decision-making processes, equitable resource distribution, and equal opportunities across the age and gender divide.

However, as has been shown in this chapter, much of the focus of ecotourist initiatives in Fiji has been on the preservation of cultural integrity and the conservation of nature. The conservation of the social, cultural and natural ecology suggests stasis. Thus, ecotourism development in Fiji has not dealt with the promises of the sustainability premise. Indeed, in many ways those promises stand in sharp contradiction to ecotourist initiatives in Fiji. At a time when the indigenous and non-indigenous peoples of Fiji are invariably integrating into the world economy, global imperatives are becoming all the more apparent. If ecotourism is to deal with the paradox of sustainability, the old dichotomies between modernity and tradition and between indigenous and non-indigenous will have to give way to a more syncretistic relationship. If not, ecotourism will become just another doomed sustainable development initiative. 


\section{Endnotes}

1. The research for this chapter is based on fieldwork that was carried out throughout 1996 and 1997. It is part of a larger study of ecotourism development in Fiji, and will form the basis of a $\mathrm{PhD}$ thesis. The research results are currently being written up in the Department of Anthropology at the University of Otago, Dunedin, New Zealand. I would like to acknowledge helpful comments on this chapter from Ian Fraser, Trisha Korth, Jacqui Leckie and Peter Wilson.

2. The Fiji Visitors Bureau hosts an ecotourism site on the World Wide Web: <http://www.fijifvb.gov.fj/ecotour/ecotour.htm>.

3. These figures come from the confidential monthly revenue summaries of the Bouma and Abaca ecotourism projects for the period between 1994 and 1996. They have been confirmed as authentic by the author.

4. Personal communication with members of the landowning unit. 
This text is taken from Confronting Fiji Futures, edited by A. Haroon Akram-Lodhi, published 2016 by ANU eView, The Australian National University, Canberra, Australia. 